\title{
The backlash of state coercion:
}

\section{Varieties of repression and their effect on mobilization}

\author{
Francisca Castro \\ Humboldt Universität zu Berlin
}

March, 2022

\begin{abstract}
The impact of police repression on protest is puzzling. While in some cases, repression can deter protest, other times it backfires, increasing mobilization and its intensity. But still, we have relatively little knowledge of exactly which repressive actions are associated with deterrence or incitement of protest activity, and why. Using novel data on protest repression in Chile, I study the effect of repressive actions over the occurrence of subsequent protest events, and whether specific forms of repression have a differentiated effect on protest dynamics. I find that two forms of repression, beatings and the use of non-lethal weapons, increase protest activity in the following day. Conversely, arrests and abuses do not influence protest occurrence. These results show that repression does not account for protest decline, but the opposite: visible and arbitrary forms of state coercion in democratic contexts have a backlash effect, increasing contentious activity.
\end{abstract}

Keywords: police repression, protests, state coercion, causal inference 


\section{Introduction}

Protests have been an important channel for people to communicate their demands and to make themselves heard. Despite the resurgence of protests in the last years? street activism has encountered severe repression. Coercion and even brutality from law enforcement agents towards protesters is not a novel practice, but it has aggravated in recent year: $2^{2}$, so much that systematic violations of civil and human rights at the hands of law enforcement officials have become a regular practice, rather than an exception, in the context of street mobilization. Such practices can inhibit the will to protest and ultimately refrain people from collective action; therefore, it is worth exploring how protest coercion through state repression can affect this form of political expression. However, it is still unclear if repression could have a differentiated effect on mobilization based on its type and the consequences that such repression entails for protesters. Since repression can change people's behavior by affecting the parameters considered into the cost-benefit decisions about dissent and their perceived risks (Young 2019), we can expect that more violent forms of repression increase such perception of danger, and therefore, dampen protest activity.

How police repression may affect both protest events and their tactics has been a central question within social movements research for decades. Unfortunately, there has been a lack of consensus about the relationship between government's coercive behavior and its influence on dissent (Sullivan et al. 2012): while sometimes repression can diminish protest activities, other times it backfires, increasing the levels and scope of these demonstrations Anisin 2016; Khawaja 1993), fueled by the outrage in the population (Della Porta and Fillieule 2004). This variety of results and considerations of sociopolitical characteristics has not been accompanied by a close examination of how different forms of repression executed by state agents may cause diverse effects on mobilization. It is important to inspect not only which forms of repression deter protest

1. According to ACLED data, we can see a remarkable increase in protest event occurrence since 2015

2. Along with a protest increase, ACLED data also shows a big increment of violence against civilians perpetrated by state forces. Unfortunately, there are no statistics regarding violence against protesters, specifically. 
but also the ones that increase it, especially considering that when attacks on demonstrators backfire, the political regime could result severely damaged (Smithey and Kurtz 2018). In such cases, the government in power may even be unable to overcome the crisis of legitimacy caused by repression when it is considered inappropriate or unjust.

The analysis of law enforcement agents' repressive behavior based on typologies was identified as a key topic for future social movements research more than a decade ago (Davenport 2007). There have been significant efforts in that regard (e.g. García-Ponce and Pasquale 2015: Curtice and Behlendorf 2021; Bautista et al. 2020), nevertheless, empirical research has not been able to capture the diversity of types of repression that take place during contemporary protests in democratic contexts, and if they affect protest cycles. In this research, I investigate the role of different police repressive actions against protesters, and their effect on subsequent mobilization, using Chile as a case study. Starting on October 18, 2019, after the announcement of an increase in public transportation fares, people took the streets to protest. Unfortunately, the repression faced by the protesters was brutal: injured civilians at the hands of the police, arrests without a clear motive, misbehavior of law enforcement officials, and abuse of power were everyday news. The protests ceased after the COVID-19 outbreak, but their extensive duration and the diversity of repressive tactics exerted by the police make Chile an appropriate setting for studying repression, making it possible to capture the progression of a social movement, and how it is affected by repressive tactics and police behavior.

Using novel data provided by the Chilean Institute of Human Rights (INDH) on police repression during the previously mentioned street protests, along with protest occurrence information obtained from the Armed Conflict Location and Event Database (ACLED), I find that certain types of repressive actions caused an increase in protest activity: beatings and the use of non-lethal weapons (such as rubber bullets, tear gas, and water cannons) increase protest events occurrence in the following day. Their influence continues after controlling for previous protest events activity. To assess the causality of these findings, I 
use CCTV cameras' locations as an instrumental variable for the occurrence of beatings and the use of non-lethal weapons. The effect of both types of repressive actions on protest occurrence remains using these models. Even when these results support recent findings related to how mobilization reacts to repression (e.g. Curtice and Behlendorf 2021; Ellefsen 2021; Aytaç et al. 2018, Smithey and Kurtz 2018), in the sense that repression sometimes can backlash and produce more contentious activity, they also offer new evidence regarding which forms of state repression produce such backlash, since I show that not all repressive forms have the same effect.

Additionally, my results challenge previous findings regarding protest deterrence when the costs and risks associated with participation increase (see Opp and Roehl 1990; Digrazia 2014), showing that this association might be too simplistic. Being beaten up by the police or being a victim of non-lethal crowd control weapons carries great risks for protesters -sometimes fatal..$^{3}$ Nevertheless, such acts increase protest activity, which shows that risks are not the main factor that explains dissuasion. In this sense, it is necessary to review the theorized inverted U-shape relationship between repression and mobilization that affirms that, after a giving threshold, police repression will actually deter mobilization. I argue that two mechanisms explain why some forms of repression cause more mobilization: the visibility of the repressive action, and their scope (arbitrary or targeted).

My research adds to the literature on the repression of social movements by presenting a new approach through the specification of how different types of repressive actions can cause particular reactions to dissent and protest. I intend to move beyond previous research which has focused on police strategies and how they affect protest (e.g. Earl and Soule 2010), highlighting instead, concrete repressive tactics that entail

3. Even when non-lethal weapons are presumably attractive to security forces because they spare the user from the traumatic psychological effects of committing violence, and minimize the public relations fallout associated with more violent methods (Smithey and Kurtz 2018), we have to keep in mind that their actual consequences are far from being non-harmful. Hundreds of protesters in Chile lost one or both eyes due to rubber bullets. Chile became the country with the highest worldwide rate of ocular trauma caused by kinetic impact projectiles during protests (Rodríguez et al. 2021). During the 2013 students' protests, one student almost died after receiving a direct impact of a water cannon. Chile is not an exception in this regard. In recent years, protesters in France also have denounced the severe injuries caused by these forms of crowd control mechanisms. 
different degrees of risk for the life and security of those who protest on the streets. Latin America has been going through a series of struggles with police brutality, along with political crises which, mostly, have exacerbated law enforcement violence against civilians. Understanding which repressive tactics backfire can contribute to the comprehension of persisting conflict in democratic contexts. As Gurr (2011) states, the public order is most effectively maintained when means are provided within for individuals to work towards the attainment of their aspirations. If the exercise of inalienable political rights encounters repression, it can severely undermine governance and overall democratic quality. 


\section{Theory}

Repression has been defined as a "physical coercion of challengers" (Tarrow 1994), a conceptualization that gives enough room to measure repression as, for example, a binary variable that captures the presence or absence of repressive actions by authorities in reaction to protest (Maduz 2020), or a continuous variable using the number of arrests during a specific protest event (Mausolf 2017). Despite extensive previous research, there have been few efforts to conceptualize and measure repression in a more disaggregated manner, allowing to assess exactly which types of repressive actions demobilize protesters, and which end up causing the opposite. Classifications such as the one elaborated by Earl et al. (2003), who distinguished six forms of police repressive tactics (police presence, limited action -e.g., negotiations--, use of barricades, use of physical force, use of weapons, and arrests) represent a valuable starting point for expanding the spectrum of police tactics that are currently used in democracies.

The crossroad about why repression may work to stop protests, but other times it does not -up to the point of increasing them instead (Bell and Murdie 2018), is at the center of the research regarding the effect of state repression on mobilization 4 Results have been mixed: while sometimes repression can effectively diminish opposition activities, other times it backfires, increasing the levels and scope of protests (Khawaja 1993). Other authors have stated that the relationship between repression and protest can be two-folded, in the sense that protest and repression may influence each other (Carey 2002; 2006; Ritter and Conrad 2016). Traditionally, the answer regarding why protest persists despite repression has focused mostly on characteristics of the movement itself -how much the movement can gain from the protest (Goldstone and Tilly 2001), or the strength of their organizational ties (Chong 1991), among other factors, rather than the characteristics of the repression itself. To contribute to this area, I look at how different forms of repression can affect protest activity, identifying the mechanisms reported in the literature regarding why this may occur. To explain the relationship between repressive

4. See Davenport (2005) and Earl (2011) for an extensive review. 
actions and protest, I focus on two areas: experienced and perceived repression (visibility) and the scope of repression (arbitrary or targeted).

\section{Experienced and perceived repression}

Even though repression is not the only state response to protest, is undeniably central to understanding social movements and movements' behavior (Della Porta 2012). As Rasler (1996) summarizes, the literature points to a positive, negative, U-shaped, and inverted U-shaped relationships between repression and dissent. Among the "positive linear" hypothesis research, it has been theorized that higher levels of repression will trigger a high level of protests, based on the assumption that if the population is faced with more repression, it will put more effort into limiting the control and power of the state and rebel against the government (Carey 2002). This theory explains situations where police repression backfires and results in more protests (Francisco 2004, Sutton et al. 2014).

Visibility is one mechanism behind this positive relationship: repressive actions can increase protest activity if they are visible enough to be perceived by outsiders of the movement. Visibility refers to the strategic processes between actors with unequal material and symbolic resources that make or prevent something from becoming public (Jiménez-Martínez 2021). Since repression works as a communicative act targeted not only at currently engaged protesters but also at the general (usually inactive) general population, it can incite more protest activity from both protesters and non-protesters (Sharp 1973). As Earl (2003) suggests, when repression becomes obvious to both protesters and the wider public, it can stimulate more mobilization. Protesters may engage in further contentious activity when repression does not manage to dissuade protest behavior, whereas non-protesters may engage in further contentious activity when they become aware of the levels of repression, which relates to the visibility of the repressive actions.

If uncommitted individuals or groups are unable to get information about state repression, they cannot experience preference changes. In such cases, increased 
mobilization after repression is unlikely (Sutton et al. 2014). During protests, there are forms of repression that cannot be carried out in private spaces, meaning that they will be noticeable for protesters and bystanders. One of the most typical forms of repression under this category is the use of crowd control mechanisms and non-lethal weapons, which may include rubber bullets, tear gas, and water cannons aimed at crowd control. Given that the visibility of these repressive measures is higher, it is also more likely to be reported in the media, reaching people that initially were not aware of these repressive responses by the state. If actions of state authorities become visible enough, private citizens could actually observe rises and falls in coercive repression (Earl 2003), granting meaning to these repressive events, which could lead to preference changes. It has been argued that when the police are perceived as "overreacting", there is a process of solidarity between those who are the direct target of repression, and more moderate (and usually larger) forces (Della Porta 1997). This may be one of the reasons why the triggers of mobilization are found in visible or excessive measures (Josua and Edel 2015), pointing to a possibility of an increase in protest activity after highly visible repressive events.

I expect that repressive actions with higher visibility to both protesters and bystanders increase subsequent protest activity. On the contrary, more covert forms of repressive actions will not have an impact, since these actions are likely to be carried outside the public eye (e.g. in police stations or mobile checkpoints). For repression to backfire, information about the event or situation needs to be communicated to receptive audiences (Hess and Martin 2006). Traditional forms of repressing protests, such as police charges and arrests, involve a degree of visibility that allows citizens to see and assess the circumstances in which they took place (García et al. 2014).

\section{Sense of injustice}

Social movement theory states that repression increases the feeling of relative deprivation (Gurr and Moore 1997). And when groups are disadvantaged, members must perceive their disadvantage as collective to feel or do something about it (Van Zomeren et al. 2004). 
Relative deprivation theory understands backfire as a public reaction of outrage to an event that is publicized and perceived as unjust; therefore, one of the key mechanisms for generating backfire is public outrage at repressive events (Hess and Martin 2006). For a repressive event to backfire, an audience must perceive the event to be unjust, which may elicit anger and, therefore, escalation (Hess and Martin 2006, Honari 2018).

Certainly, the perception of the event as unjust relates to the level of visibility that specific repressive actions entail. Following the argument that repressive actions with higher visibility increase subsequent protest activity, I state that among the visible repressive actions, those that appear to be more arbitrary (in the sense of affecting large portions of not only protesters but also bystanders) are the ones that will cause a greater increase in subsequent protest activity. When using crowd dispersion techniques, the target is less likely to be specific "trouble-makers" individuals, and more likely to be an anonymous collective, focusing their coercive measures in indiscriminately dispersing the entire crowd (Waddington 1997). This can increase the uncertainty about the aims of the intervention, which can subsequently provoke protest escalation (Della Porta 1997). Under these conditions, repression can be an escalation factor since it may elicit anger when it is perceived as unjust deprivation (Honari 2018). Since these crowd dispersion techniques aim to large portions of protesters, therefore increasing the risks of being affected by them, this can increase willingness to engage in collective action (Ayanian and Tausch 2016).

The legitimacy of the repressive action is also important when considering the arbitrariness. What happens when the repressive actions are targeted (unlike the ones that affect large portions of protesters and bystanders), but do not comply with established protocols for the use of public force? More recent classifications of police tactics have focused on acts of police brutality, considering illegal arrests, coercion of witnesses, fabrication of evidence, and the use of torture to extract confessions (Magaloni and Rodriguez 2020) as modern police tactics. Even when Magaloni and Rodriguez (2020) focus on state transgressions committed by law enforcement agents not against protesters, but accused criminals, their classification is useful to get an 
approximation of the wide array of tactics and procedures that law enforcement agencies carry out. Therefore, I theorize that repressive actions that encompass a violation of protocols and abuses will cause an increase in subsequent protest events, despite their targeting. This presents a counterpoint to previous research that has stated that less overt forms of repression minimize the risk of dissent (Esberg 2021) since it is likely that the forms of repression that do not comply with protocols are hidden from the public eye.

Considering this theoretical scheme, the hypotheses that will guide this research are:

Hypothesis $\mathbf{1}(\mathbf{H} \mathbf{1})$ : Repressive actions that encompass visibility and arbitrariness will increase subsequent protest activity.

Hypothesis 2 (H2): If a repressive action lacks arbitrariness but is deemed as illegitimate, it will increase subsequent protest activity if it is visible.

Hypothesis $3(\mathbf{H} 3)$ : If a repressive action is neither visible nor arbitrary, it will not affect subsequent protest activity, despite being deemed as illegitimate. 


\section{Context: The Chilean Social Outburst}

The so-called "social outburst" (Estallido Social) that began in Chile in October 2019 could be categorized, in Tarrow's words, as a "turbulent point in history" (Tarrow 1994). The Chilean case represents an interesting puzzle to study police repression and its effects since the protests and riots that unfolded over the next following months were characterized by their frequency, their high turnout, and their occurrence in both big and small cities. But, unfortunately, this period of social mobilization was marked by brutal repression carried out by law enforcement agents. The Chilean protests allow us to trace different repressive tactics and their effect on mobilization trends. That protests unfolded for almost six months allows an assessment of the relationship beyond particular contentious cycles.

After the return of democracy posterior to the 1989 Plebiscite that ended Augusto Pinochet's dictatorship, multiple social movements unfolded in Chile, being the students' movements of 2006 and 2011 the most emblematic ones. Even when these two movements achieved significant political victories, such as the repeal of the General Education Law (Ley General de Educación, LGE), and developed steady protest activity for months, neither had the same level of protest frequency and sustained turnout than the 2019 Estallido. What unfolded for almost six months was a real routine of protest activity with little organization. In Santiago, people gathered in Plaza Baquedano (later renamed Plaza Dignidad by the protesters and supporters of the movement) almost every afternoon, with Fridays being the day with the highest attendance of people protesting. Similar dynamics occurred in other cities. According to data provided by the national police (Carabineros de Chile), over 4,300 protest events occurred from October 18, 2019, to March 31, 2020, across the country.

Even when protests and riots started in the capital Santiago after the announcement of an increase in public transportation fares of 30 Chilean pesos, they rapidly took place in other cities as well. After the announcement of the tariff increase, students from several public high schools of the capital organized mass evasions of public transport, specifically in subway stations (Baeza 2019). During the following week, police officers 
were constantly monitoring the entrances of the stations, closing accesses to have greater control over who entered. The most critical stations were closed for several hours per day. On the afternoon of Friday, October 18, the situation escalated, and multiple subway stations were set on fire, allegedly by protesters.

As a response to the fires in the subway stations, president Sebastián Piñera declared a state of emergency, and a subsequent curfew started on the $19^{\text {th }}$ of October. Riots occurred in other parts of the country during that weekend, and the repressive actions of the police exacerbated the social unrest. The support by the Government towards police's actions translated, in the last term, into more social unrest and discontent. Despite the constant pressure from the Government to "return to normality", and the announcement of an action plan called "New Social Agenda" (Nueva Agenda Social) (Rogel 2019) which, according to the Government, aimed to solve the main problems and struggles of the population, social unrest did not stop. The feeling that the Government's measures did not aim at structural reforms, and the high levels of repression, generated a constant state of skepticism and anger in the society. Protests and riots lasted until the COVID-19 outbreak in mid-March 2020.

According to data provided by Carabineros de Chile, more than five million people took part in the protests between October 2019 and March 2020 $5^{5}$ This high turnout did not prevent demonstrators from being physically repressed. The level of repression exercised mostly by Carabineros, but also by other law enforcement institutions such as the military and the marines, was unprecedented for the democratic history of the country. International organizations such as Human Rights Watch and Amnesty International acted as observers of what was happening on the streets, and continuously called out the disproportionate use of force against protesters, the use of lethal weapons, and persistent non-compliance with protocols that ended up with thousands of people with eye injuries

5. This data was provided as a response to a request through Transparency Law. Attendance is calculated based on a methodology used by Carabineros, which considers two different counting mechanisms: for low turnout protests, the calculation is according to the assessment of the police personnel present at each event; for protests with high turnout, the calculation is based on the use of drone images and geographic function application that divides the territory into polygons based on the density of the attendees and the area in square meters. 
caused by rubber bullets (Amnesty International 2020). The severity of the accusations against Carabineros and their practices caused considerable outrage in the population. Abuses were not limited to what happened on the streets while protesting, but also in other places. The media informed several cases of undressing in police stations, even of minors (INDH 2019), along with other occurrences of gender-based violence such as beatings and rape threats ( Rojas 2019). Since the frequency and participation of protests were relatively steady over the upcoming months, despite the variety and intensity of repressive actions committed by Carabineros and other law enforcement institutions, it is worth examining what was the effect of these repressive actions and whether they are linked with an increase in protest activity. 


\section{Research Design}

\section{Variables and Measurement}

Using data available in the Armed Conflict Location and Event Database (ACLED), I gathered information at the municipal level (lowest administrative unit) of the dependent variable protest events occurrence. ACLED database identifies different event types associated with social mobilization, such as battles, explosions, protests, and riots, as well as their exact date and location, using national and international news as sources of information. ${ }^{6}$ I considered all the events categorized as protests or riot: $\mathrm{7}^{7}$ that occurred between the October 18, 2019, until March 31, 2020, along with information of their place of occurrence and date. I supplemented this protest occurrence information with data on repressive actions by law enforcement officials provided by the Chilean Institute of Human Rights (INDH). The INDH elaborated an extensive database containing all judicial actions from civilians who claim to have been subjected to any type of abuse, excessive violence, or violation of basic rights by state agents. I coded the repressive acts into four main categories: abuses, arrests, beatings, and use of non-lethal weapons. For details on the construction of these categories, see Appendix A.

Combining these two sources of information, 235 municipalities (from 346) presented at least one protest event or one action of repression during the mentioned period. Based on that, I constructed a time-series database comprising the total of 346 municipalities for each of the 166 days, getting a final data set of 57,436 observations. Table 1 summarizes the distribution of repressive actions and contentious events by region, month, type of repressive action, and type of contentious event for those observations that have at least one protest or repressive event.

6. Events data sources like ACLED are sometimes criticized for their heavy reliance on media sources (Eck 2012); however, its focus on desegregated data of events on a specific day in an exact location is useful to obtain contextually rich conclusions (Raleigh et al. 2010).

7. ACLED (2019), defines protest as a public demonstration in which the participants do not engage in violence, though violence may be used against them. Conversely, riots are violent events where demonstrators or mobs engage in disruptive acts (e.g. rock-throwing, property destruction, etc.). I included both measures indistinctly since Chilean protest dynamics usually present a co-existence of them. 
Table 1: Distribution of repressive actions and contentious events

\begin{tabular}{lcc}
\hline & Repressive actions & Contentious events \\
\cline { 2 - 3 } Region & $34.1(945)$ & $24.2(591)$ \\
Metropolitan Region & $65.9(1,830)$ & $75.8(1,853)$ \\
Other Regions & & \\
\hline Month & $49.4(1,371)$ & $24.0(586)$ \\
October 2019 & $33.3(923)$ & $41.2(1,007)$ \\
November 2019 & $5.10(140)$ & $9.4(231)$ \\
December 2019 & $5.3(148)$ & $8.6(210)$ \\
January 2020 & $1.7(48)$ & $4.0(98)$ \\
February 2020 & $5.2(145)$ & \\
March 2020 & & \\
\hline Type of Repressive Action & $5.5(152)$ & \\
Abuses & $9.9(274)$ & \\
Arrests & $34.5(956)$ & \\
Beatings & $50.2(1,393)$ & \\
Non-lethal Weapons & & \\
\hline Type of Contentious Event & & \\
Protests & & \\
Riots & & \\
\hline Total (N) & & \\
\hline Note: Etrat & \\
\hline
\end{tabular}

Note: Entries in percentages with $\mathrm{N}$ in parenthesis.

The third source of information was provided by the Chilean Ministry of Transports and comprises the location of CCTV cameras across the country. Even when the CCTV system is in charge of a Ministry that does not oversee public security, vigilance through CCTV cameras is one key component of the telesurveillance system elaborated by the Department of Crime Prevention, which is part of the Ministry of Interior and Public Security. Both security offices at the municipal level and Carabineros have access to this system. 575 cameras were identified throughout the country, along with their locations and the start date of their operation. The register also includes information on the exact date when the operation of a camera ceased, which allows capturing if a camera stopped working during the protest period, counting the real number of cameras working 
for each date. I included information on the number of operating CCTV cameras in the contentious activity database for each specific location (at the municipal level) and date.

\section{Estimation}

Taking advantage of the panel structure of the data on daily contentious activity and repressive actions at the municipal level, I estimated fixed effects models to avoid possible omitted variable bias caused by invariant non-accounted time or spatial factors. Additionally, following the literature that considers lagged variables into the study of social movements and protests - e.g. Earl and Soule (2010), Opp and Roehl (1990), and Beck and Katz (1996), and the use of lagged explanatory variables aimed to eliminate serial correlation of the errors (Beck and Katz 2011), I included lagged explanatory variables of the dependent variable protest events occurrence, as well as lagged specifications for each of the four types of repressive actions, since I am interested in how previous experiences with protest repression affect subsequent protest occurrence.

The two-way fixed-effects (TWFE) model estimation with lagged variables on the right side of the equation has the following structure:

$$
y_{i, t}=\alpha_{i}+\delta_{t}+\beta X_{i, t-n}+\rho Y_{i, t-n}+\epsilon_{i, t}
$$

where $X$ is a vector that includes the four types of repressive actions in their lagged form, with an effect associated with municipality $i$ at time $t$ for each day. $\rho Y_{i, t-n}$ is the vector for lagged protest events occurrence. Since the database presents the variable protest events occurrence for both time (daily) and place (municipalities), Equation (1) presents units $i=1, \ldots, N$, which are observed over periods $t=1, \ldots, T$, for a total of $N \times T$.

\section{Instrumental Variable}

To assess the causal effect of different types of repressive actions on protest events occurrence, we need to rule out the possibility that the error term includes some unobserved attributes that determine both protest events occurrence and the different types of repressive actions. One example of such attribute could be the news cycle, or 
public declarations from the government, just to name a few. If the repressive actions are correlated with the error term, it means that they are endogenous. Following Dunning (2012), if we encounter a situation where inferring the impact of an independent variable on a given dependent variable is difficult because of reciprocal causation or confounding, which may pose a problem for causal inference, one solution could be to find an instrumental variable that is correlated with the main independent variable repressive actions but that is not influenced by the dependent variable protest events occurrence or correlated with its other causes. In other words, the motivation for adding an instrumental variable to the estimation is that the requirement of the zero-covariance between $X_{i}$ and $u_{i}$ is violated when $X_{i}$ is systematically related to unobserved causes of $Y_{i}$ (Sovey and Green 2011). Given that some variables included in $X_{i, t-n}$ from Equation (1) are correlated with the error term, a two-stage least-squares (2SLS) could be a good approach to solve such issue, and to provide more robustness to the results.

A good instrumental variable must be highly correlated with the explanatory variable while remaining uncorrelated with the errors (Belsley et al. 1980). A variable $Z$ can be referred to as an instrument when three conditions are met: $Z$ has a causal effect on $X$ (relevance), $Z$ affects the outcome $Y$ only through $X$ (exclusion), and $Z$ does not share common causes with the outcome (exogeneity) $Y$ (Hernán and Robins 2006). The first assumption was tested through a first-stage regression following Equation 2 (results available in Appendix C):

$$
\text { Repressive Actions }=\gamma_{0}+\gamma_{1} Z+\gamma_{2} W+\epsilon
$$

where $W$ are the exogenous control variables with a coefficient of $\gamma_{2}$, and $\epsilon$ the error term. $Z$ is the vector for the number of active CCTV cameras at that date and geographical location (municipality). This IV works if we assume it does not influence the occurrence of protest events, which is related to the exclusion assumption. In this regard, the presence of CCTV cameras only affects the occurrence of protest events through repressive actions. CCTV cameras allow the police to rapidly respond to crowd gatherings and emerging protests. Therefore, CCTV cameras decrease the likelihood of police violence, as they can 
resort to other means. On the contrary, if the availability of CCTV cameras is limited, is more likely that police only respond when crowds are already harder to manage, having to escalate the situation if they want to exercise control, increasing the chances of controlling through violence. One can assume that cameras' locations do not influence the occurrence of protest events (cameras are usually in very high places, disguised near traffic lights, and with no signs pointing to their existence) but it can influence police response to a protest and therefore, the propensity to commit violent acts. Additionally, since the database on cameras' locations shows the date of installments of cameras, I rule out the possibility that there were new cameras installed exactly in the municipalities with more protests (because, in fact, there were no new cameras installed during the protest period).

Regarding the last assumption, exogeneity, it is necessary to establish that there is no relationship linking the location of CCTV cameras and protest events occurrence, caused by variables that are not included in the models. Arguably, one can say that cameras are installed in big avenues where protests are likely to take place. However, the two municipalities with more cameras are two socioeconomically well-off municipalities in the Metropolitan Region, which experienced fewer protests events. This shows that, most likely, cameras' availability is more related to the socioeconomic status of a municipality, which effect can be accounted for through TWFE models. 


\section{Results}

Figure 1 shows the occurrence of repressive actions throughout the country, from October 18, 2019, until March 31, 2020. We can see a remarkable occurrence of repression in the Metropolitan Region, which is related to the greater proportion of protests concentrated in that area.

Figure 1: Distribution of repressive actions throughout Chile

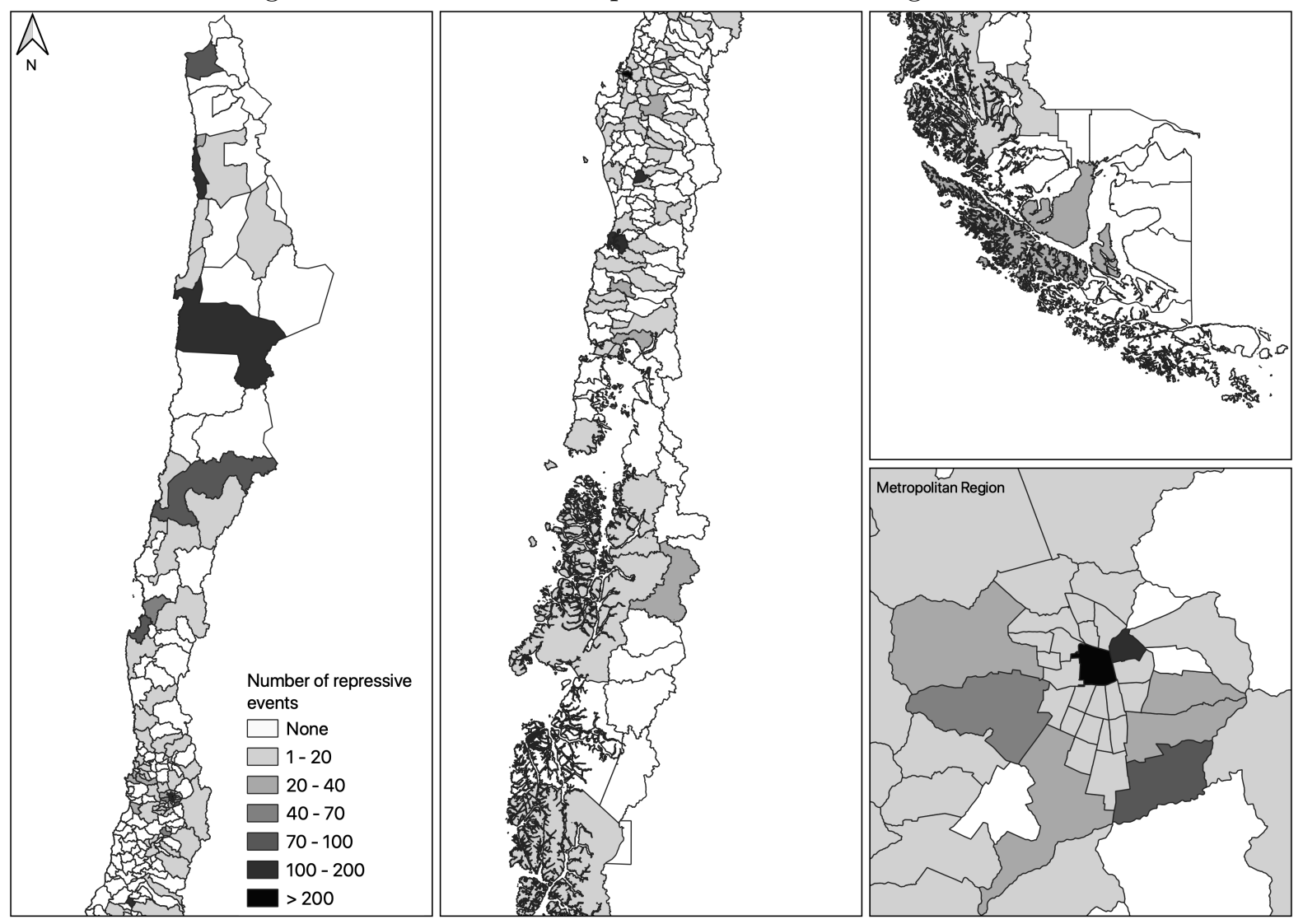

Source: Own elaboration using INDH data

As a baseline model, I estimated an OLS model to assess the relationship between the different types of repressive actions, using protest events occurrence as the dependent variable. Table 2 shows the standardized coefficients for this baseline model, which includes all four types of repressive actions at time $t$. All the types of repressive actions are statistically significant in explaining protest events occurrence -which is obvious since repression is less likely to occur when there are no events of protest happening. However, this model is still interesting to assess the prevalence of specific types of repression and their strength. The results point to the relevance of the use of 
non-lethal weapons when considering protest events occurrence as an independent variable: a one standard deviation increase in the use of non-lethal weapons implies an increase in protest by 0.24 standard deviations. This finding shows that to be a shooting victim, being gassed, wetted with chemicals, or impacted with water cannons, is associated with a greater incidence of protest events. Additionally, we can see that none of the types of repression have a deterrent effect on protest occurrence.

Table 2: Effect of repressive actions on protest occurrence

\begin{tabular}{|c|c|}
\hline & Model 1 \\
\hline Abuses & $\begin{array}{c}0.047^{* * *} \\
(0.004)\end{array}$ \\
\hline Arrests & $\begin{array}{c}0.045^{* * *} \\
(0.004)\end{array}$ \\
\hline Beatings & $\begin{array}{c}0.201^{* * *} \\
(0.004)\end{array}$ \\
\hline (Use of) Non-lethal weapons & $\begin{array}{c}0.237^{* * *} \\
(0.004)\end{array}$ \\
\hline Observations & 57,436 \\
\hline $\mathrm{R}^{2}$ & 0.143 \\
\hline Adjusted $\mathrm{R}^{2}$ & 0.143 \\
\hline Residual Std. Error & 0.233 \\
\hline F Statistic & $2,398.706^{* * *}$ \\
\hline
\end{tabular}

Beatings also seem relevant to explain the occurrence of protest events, although with a smaller effect. This smaller, but still statistically significant effect, might be explained by their targeted component: unlike the use of non-lethal weapons, beatings (and also abuses and arrests) have a more targeted, one-to-one component. This can be one reason why they do not produce the same mobilizing effect as the use of non-lethal weapons, as the general population may think to a lesser extent they will be victims of such actions.

\section{Fixed Effects and Instrumental Variable}

Since I am interested in exploring how previous acts of repression affect subsequent protest events, I estimated new models with lagged independent variables for times $t-1$ and $t-2$, 
that is, one and two days before, respectively. The reason for only including up to two lags is the duration of the effect: only previous protest events at time $t-2$ are significant to explain protest occurrence, while none of the repressive actions at that time are (see Appendix B). Table 3 shows the TWFE panel linear models with lagged variables. Model 2 only has lagged variables for $t-1$, whereas Model 3 includes $t-1$ and controls for $t-2$.

Table 3: Effect of previous repressive actions on protest occurrence

\begin{tabular}{lcc}
\hline & Model 2 & Model 3 \\
\hline Abuses $_{t-1}$ & $0.016(0.014)$ & $0.014(0.014)$ \\
Arrests $_{t-1}$ & $0.013(0.009)$ & $0.004(0.010)$ \\
Beatings $_{t-1}$ & $0.051^{* * *}(0.013)$ & $0.041^{* * *}(0.011)$ \\
Use of $)$ Non-lethal weapons $_{t-1}$ & $0.071^{* * *}(0.011)$ & $0.054^{* * *}(0.011)$ \\
Protest events $_{t-1}$ & $0.225^{* * *}(0.033)$ & $0.198^{* * *}(0.030)$ \\
\hline Controls $^{*}$ No & Yes \\
FE Municipality & Yes & Yes \\
FE Time & Yes & Yes \\
\hline Observations & 57,090 & 56,744 \\
R $^{2}$ & 0.079 & 0.099 \\
Adjusted R & 0.071 & 0.090 \\
F Statistic & $972.564^{* * *}$ & $614.694^{* * *}$ \\
\hline
\end{tabular}

Note: Entries are standardized coefficients with robust standard errors in parenthesis.

Dependent variable: protest events occurrence. Controls: repressive actions at time $t-2$. ${ }^{*} \mathrm{p}<0.1 ;{ }^{* *} \mathrm{p}<0.05 ;{ }^{* * *} \mathrm{p}<0.01$.

Both Non-lethal weapons t-1 $_{t}$ and Beatings $s_{t-1}$ stand out as consistent variables across both models: an increase of one standard deviation for each repressive action is associated with a 0.05 and 0.04 standard deviations more, respectively, in the occurrence of protest events in the following day, controlling for repressive actions that took place during $t-2$ (Model 3). These results are consistent with Hypothesis 1, which posits that arbitrary repressive actions with higher visibility for both protesters and bystanders will have a bigger effect on increasing protest activity. The use of non-lethal weapons is arguably the most visible and arbitrary form of police repression: they can only be carried out in public spaces, their use is impossible to hide, and they have a powerful impact on protesters and passersby. It was also argued previously that this repressive action entails 
higher arbitrariness: they might affect not only protesters but also people who were not involved in the demonstration. This might cause a strong feeling of injustice in the general population, an emotion that can also affect people's cost-risk evaluation.

Conversely, repressive actions that are visible, yet not arbitrary, appear to have a smaller effect on increasing mobilization activity compared to actions that are visible and arbitrary (such as the use of non-lethal weapons). Police beating protesters is a visible but targeted action; however, inflicting physical force against protesters is likely to have lesser social acceptance as a way of coercing protesters. This confirms Hypothesis 2 about the effect of visible and targeted actions, through their consideration as illegitimate. This is not the case for arrests, an action that is also visible and targeted, but entails a higher degree of legitimacy within the rule of law. Finally, abuses do not seem relevant in explaining subsequent protests, which is consistent with Hypothesis 3 . due to the lack of visibility and arbitrariness that this repressive action holds, it is unlikely to foster further protest occurrence, regardless if they are deemed as illegitimate or not.

\section{Instrumental Variable: CCTV cameras}

Since both the use of non-lethal weapons and beatings were the repressive actions that caused an increase in protest occurrence on the following day, I estimated 2SLS models to assess their actual causal effect over protest events occurrence. In the first stage, I used the instrument $Z$ (CCTV cameras) to predict the endogenous independent variables non-lethal weapons (Equation 3) and beatings (Equation 4), controlling for the lagged version of protest events. Equations 4 and 5 present the second-stage (2SLS) estimation for the dependent variable protest events occurrence, using the predicted versions of the independent variables obtained through the first-stage, controlling by $X_{i, t-2}$, the second lag of the repressive action. For all equations, $\rho Y_{i, t-1}$ represents the lagged specification of protest events occurrence.

Stage 1 Equations:

$$
\text { Beatings }_{t-1}=\gamma_{0}+\gamma_{1} Z_{t-1}+\rho Y_{i, t-1}+\epsilon
$$




$$
\text { Non-lethal } \text { Weapons }_{t-1}=\gamma_{0}+\gamma_{1} Z_{t-1}+\rho Y_{i, t-1}+\epsilon
$$

Stage 2 Equations:

$$
\begin{gathered}
\text { Protest Events }_{i, t}=\alpha_{i}+\delta_{t}+\beta_{1} \text { Non-let } \widehat{\text { hal W }} \text { eapons }_{i, t-1}+\rho Y_{i, t-1}+X_{i, t-2}+\epsilon_{i, t} \\
\text { Protest Events }{ }_{i, t}=\alpha_{i}+\delta_{t}+\beta_{1} \widehat{\text { Beatin }_{i, t-1}}+\rho Y_{i, t-1}+X_{i, t-2}+\epsilon_{i, t}
\end{gathered}
$$

Before interpreting the results of the 2SLS model, it is worth assessing briefly the quality of the instruments. Appendix $\mathrm{C}$ presents the evaluation of the assumptions of the instrument, along with other robustness tests. Through them, the use of CCTV cameras proved to be relevant, exogenous, and not a direct cause of the outcome. Table C.1 probes that CCTV cameras are statistically significant in explaining the dependent endogenous variables beatings and non-lethal weapons, which correspond to the two repressive actions that resulted statistically significant in their lagged specification (Model 2 and 3). Additionally, the convention suggests that an F-statistic over 10 is proof of a sufficiently convincing argument, which is fulfilled for both cases. 
Table 4: 2SLS Models of repressive actions over protest events occurrence

\begin{tabular}{lcc}
\hline & Model 4 & Model 5 \\
\hline Beatings $_{t-1}$ & $\begin{array}{c}3.249^{* * *} \\
(0.944)\end{array}$ & \\
(Use of) Non-lethal Weapons ${ }_{t-1}$ & & $3.126^{* * *}$ \\
& & $(0.867)$ \\
\hline First Stage & & \\
CCTV Cameras & $0.364^{* * *}$ & $0.331^{* * *}$ \\
& $(0.080)$ & $(0.079)$ \\
Wald Test & $7.181^{* * *}$ & $3.509^{*}$ \\
\hline Controls & Yes & Yes \\
FE Municipality & Yes & Yes \\
FE Time & Yes & Yes \\
\hline Observations & 56,744 & 56,744 \\
F Statistic & $403.486^{* * *}$ & $443.210^{* * *}$ \\
\hline
\end{tabular}

Note: Entries are standardized coefficients with robust standard errors in parenthesis. Dependent variable: protest events occurrence.

Controls: protest events at time $t-2 .{ }^{*} \mathrm{p}<0.1 ;{ }^{* *} \mathrm{p}<0.05 ;{ }^{* * *} \mathrm{p}<0.01$

Regarding the results of the second stage, models 4 and 5 estimate the causal effect of beatings and the use of non-lethal weapons, respectively, for both $t-1$ and $t-2$ periods, using CCTV cameras as the IV. When the endogenous part of the independent variables is extracted through 2SLS models, their effect increases: a one-standard-deviation increase of beatings carries 3.25 standard deviations more in the occurrence of protest, and 3.13 standard deviation more for the case of non-lethal weapons. From these models it is possible to state that the effect of beatings and non-lethal weapons on protest events occurrence is relevant and consistent. Instead of deterring protest, both repressive actions have the opposite effect on mobilization, increasing their occurrence. 


\section{Description of the mechanisms}

How can specific repressive actions increase the occurrence of protests when such crowd control mechanisms are supposed to do exactly the opposite? Tilly (1978) already identified that repression increases the costs of collective action, and therefore has negative effects on mobilization. Following that logic, we could expect repressive actions that increase the costs and risks of mobilization to have a deterrent effect. This argument is aligned with recent studies which have shown that people engage less in street protests when their perceptions of violence and risk increase (Dave et al. 2020). Through the analysis of novel data and the use of causal inference, I have shown that this is not the case, at least not for repression that involves two very typical forms of crowd control used in protests in democratic contexts: beatings, and non-lethal weapons such as rubber bullets, water cannons, and tear gas.

One reason why the use of non-lethal weapons sparks protests instead of deterring them is their visibility. When the police or other law enforcement agency uses tear gas or water cannons, this is evident not only to the people who are protesting at a given time but also to people that may not be engaged with the protest. Immediate exposure effects, such as irritation to the eyes, nose, mouth, and skin, are largely documented (Blain 2003), along with how the indiscriminate use of tear gas affects mostly residential areas and subway stations (Chan et al. 2019). Therefore, in contrast to other forms of repression that may be not so clear for the rest of the protesters and pedestrians (such as arrests or abuses), the use of non-lethal weapons is by far more obvious. Being a witness to this type of repression, or even being informed about it, may have a radicalization component (Opp and Roehl 1990), triggering activism. In this sense, the opposite of the so-called "selective targeting" occurs: the punishment is not directed at individuals suspected of engaging in protest activities, reducing the willingness to engage in or support political action (Kearns et al. 2020), but to a bigger group, since the costs of participation are not only paid by those who participate but also by bystanders.

Although the use of rubber bullets, tear gas, and water cannons is categorized as "non-lethal" weapons, their actual consequences are far from innocuous. Even when 
they are supposed to inflict only superficial painful injuries, rubber bullets (also called kinetic impact projectiles, KIPs) can cause significant morbidity and mortality, much from it from penetrative injuries and head, neck, and torso trauma, including ocular trauma (Haar et al. 2017). For the case of Chile, just between October 18 and November 30, 2019, 259 patients sought care due to ocular trauma at the Eye Trauma Unit at Hospital Salvador, one of the biggest hospitals in the Metropolitan Region (Rodríguez et al. 2021). But the devastating effects of KIPs in Chile unfortunately are not an isolated event: there are documented cases of the fatal consequences of this type of ammunition in Northern Ireland (Rocke 1983), Palestine (Jaouni and O'shea 1997), and France (Lartizien et al. 2019), among others. Additionally, the lack of control over the consequences entailed by the use of a repressive instrument, such as rubber bullets or KIPs, can increase the feeling of arbitrariness and injustice regarding the exercise of the repressive action. And, as such, when repression is exercised indiscriminately, people will respond by decreasing their nonviolent protest behavior and will adopt violent behavior instead (Lichbach 1987). Repression can increase mobilization if it is regarded as illegitimate or unjustified Opp 1994).

I previously argued that the effect of the use of non-lethal weapons on the subsequent occurrence of protest was related to their visibility and arbitrariness. However, police beatings are also a type of repressive action that increases protest, despite being targeted, although still visible. Considering that arrests did not seem to influence subsequent protests and that both actions share visibility and targeting, one reason why beatings seem to influence protests can be related to the legitimacy of the action. Della Porta (2012) identified key dimensions within the classification of repressive forms, distinguishing between "hard" and "soft" dimensions, according to the degree of force involved, and "dirty" versus "lawful", according to the degree of respect for legal and democratic procedures. Public repudiation of beatings by law enforcement officers may be an important factor explaining why this type of repression leads to more protests, especially if we keep in mind that when challengers frame repressive actions as illegitimate sanctions of dissident behavior, they can find new incentives to mobilize 
against the system that sanctioned them (Francisco 2004, Sullivan et al. 2012).

Finally, since beatings and the use of non-lethal weapons can have devastating and arbitrary consequences, it comes with no surprise that, when these repressive tactics develop, they become part of the news cycle rather promptly, which can cause further mobilization. This, added to the fact that there have been no reparations to the victims nor a robust response from Sebastian Piñera's government to deal with these calamities, a continuous flow of information has been generated regarding the cases and the victims, which can contribute to the maintenance of these human rights violations in the public discussion. When protesting without facing repression becomes a rare possibility, it can also affect perceptions of how much the current regime respects basic political rights. In this regard, erosion of rights and state repression are identified as structural threats that act as negative conditions, intensifying existing grievances and creating new ones in stimulating collective action (Almeida 2019). Specific cases of serious injuries caused by the use of non-lethal weapons such as rubber bullets, tear gas, and water cannons, caused a great commotion in Chilean society. The case of Gustavo Gatica, a college student who was blinded by the shot of rubber bullets on November 8, 2019, or Fabiola Campillay, who was blinded after a police officer shot a tear gas right to her face less than two meters away while she was waiting for the bus to go to work the night of November 26, 2019, are cases that are deeply engraved in the collective memory. 


\section{Conclusion}

In this paper, I studied the role of specific types of repressive actions against civilians during protests, in inhibiting or encouraging the occurrence of subsequent contentious events. In the literature on social movements, there is little consensus on whether state coercion and police repression actually work in preventing protest behavior, or if they backfire. Given that this association is very context-dependent, I examined how this relationship unfolds in the case of the Chilean protests that took place starting October 2019. My main finding was that the unfolding of protest events will depend, partly, on the type of repression that has occurred in days close to the protest. Specifically, police beatings and the use of non-lethal weapons aimed at crowd control are the two types of repressive actions that explain the increase in subsequent protest occurrence. This impact is sustained through different model specifications. This finding reinforces previous research on the effect of police repression on social movements, identifying that there are cases where such repressive acts backfire, fostering protests.

The study of the consequences of repression has always been a challenge for social movements researchers: not only data on police repression is scarce and hard to get but also there are a series of endogeneity problems associated with it, since the likelihood of realized dissent is endogenous to repression and unobservable (Ritter and Conrad 2016). I try to sort that difficulty by adding instrumental variables to my estimations. However, some problems remain, the main one related to the reliability of the account on protest events. Since there is no official institution in Chile dedicated to registering protest events occurrences, I had to look for other sources of information. ACLED data, even when it is extremely useful for studying protest, it still has an inherent bias because it uses the news as a source of information. This probably causes an under-report of protest events, and likely small cities with spontaneous protest events are the ones more affected by it.

In the future, it is necessary to consider a geographical perspective and to examine whether the response via protest occurs differently in some cities. Historically, conflict has had a regional development in Chile: the south is marked by the Mapuche conflict, while the center and the north are characterized by environmental issues, engaging 
people in conflict with both the government and private corporations. I would like to explore how geographical characteristics can affect how people respond to police violence. Additionally, it would be interesting to examine how protest engagement could foster other types of political participation, especially considering that a constituent process is being developed in Chile for the elaboration of a new constitution through a constituent convention. Given that other Latin American countries have also experienced long periods of social mobilization and unrest in the last years, a comprehensive analysis of the link between protest and political behavior in institutionalized arenas would contribute to a better theoretical understanding of the scope of the effects of mobilization and contentious activities. 


\section{References}

ACLED. 2019. Armed Conflict Location \& Event Data Project Codebook. Technical report. Accessed January 24, 2022. https://www.acleddata.com/wp-content/ uploads/dlm_uploads/2017/10/ACLED_Codebook_2019FINAL_pbl.pdf.

Almeida, Paul D. 2019. "The Role of Threat in Collective Action." In The Wiley Blackwell Companion to Social Movements, 2nd ed. Oxford: John Wiley \& Sons, Ltd.

Amnesty International. 2020. Eyes on Chile: Police violence and command responsability during the period of social unrest. Technical report. Accessed December 1, 2020. https: //www.amnesty.org/download/Documents/AMR2231332020ENGLISH.PDF.

Anisin, Alexei. 2016. "Violence begets violence: Why states should not lethally repress popular protest." International Journal of Human Rights 20 (7): 893-913.

Ayanian, Arin H., and Nicole Tausch. 2016. "How risk perception shapes collective action intentions in repressive contexts: A study of Egyptian activists during the 2013 post-coup uprising." British Journal of Social Psychology 55 (4): 700-721.

Aytaç, S. Erdem, Luis Schiumerini, and Susan Stokes. 2018. "Why Do People Join Backlash Protests? Lessons from Turkey." Journal of Conflict Resolution 62 (6): 1205-1228.

Baeza, Angélica. 2019. Evasión masiva de alumnos del Instituto Nacional en el Metro termina con denuncia en Fiscalía y medidas de contención. Accessed February 22, 2022. https://www.latercera.com/nacional/noticia/evasion-masiva-alumnos-delinstituto-nacional-metro-termina-denuncia-fiscalia-medidas-contencion/857409/

Bautista, Maria Angélica, Felipe González, Luis R. Martínez, Pablo Muñoz, and Mounu Prem. 2020. "The Geography of Repression and Opposition to Autocracy." American Journal of Political Science Forthcoming.

Beck, Nathaniel, and Jonathan Katz. 1996. "Nuisance vs. Substance: Specifying and Estimating Time-Series-Cross-Section Models." Political Analysis 6:1-36.

Beck, Nathaniel, and Jonathan N. Katz. 2011. "Modeling Dynamics in Time-Series-Cross-Section Political Economy Data." Annual Review of Political Science 14 (1): 331-352.

Bell, Sam R., and Amanda Murdie. 2018. "The apparatus for violence: Repression, violent protest, and civil war in a cross-national framework." Conflict Management and Peace Science 35 (4): 336-354.

Belsley, David A., Edwin Kuh, and Roy E. Welsch. 1980. Regression Diagnostics: Identifying Influential Data and Sources of Collinearity. Wiley Series in Probability and Statistics. Hoboken, NJ, USA: John Wiley \& Sons, Inc. 
Blain, Peter G. 2003. "Tear Gases and Irritant Incapacitants." Toxicological Reviews 22 (2): 103-110.

Carey, Sabine. 2006. "The Dynamic Relationship Between Protest and Repression." Political Research Quarterly 59 (March): 1-11.

— 2002. "Uncovering the Dynamics of Domestic Conflict: A Time-Series Analysis of Protest and Repression in Latin America and Sub-Saharan Africa." In ECRP Joint Sessions.

Chan, Emily Ying Yang, Kevin Kei Ching Hung, Heidi Hoi Yi Hung, and Colin A. Graham. 2019. "Use of tear gas for crowd control in Hong Kong." The Lancet 394 (10208): 1517-1518.

Chong, Dennis. 1991. Collective Action and the Civil Rights Movement. American Politics and Political Economy Series. University of Chicago Press.

Curtice, Travis B., and Brandon Behlendorf. 2021. "Street-level Repression: Protest, Policing, and Dissent in Uganda." Journal of Conflict Resolution 65 (1): 166-194.

Dave, Dhaval, Andrew Friedson, Kyutaro Matsuzawa, Joseph J. Sabia, and Samuel Safford. 2020. Black Lives Matter Protests and Risk Avoidance: The Case of Civil Unrest During a Pandemic. NBER Working Papers 27408.

Davenport, Christian. 2005. "Introduction: Repression and Mobilization: Insights from Political Science and Sociology." Repression and Mobilization, vii-xli.

- 2007. "State repression and political order." Annual Review of Political Science 10:1-23.

Della Porta, Donatella. 2012. "Social movements and the state: Thoughts on the policing of protest." In Comparative Perspectives on Social Movements. Cambridge University Press.

1997. "The policing of protest: Repression, bargaining, and the fate of social movements." African Studies 56 (1): 97-127.

Della Porta, Donatella, and Olivier Fillieule. 2004. "Policing Social Protest." In The Wiley Blackwell Companion to Social Movements. New Jersey: Blackwell Publishing Ltd.

Digrazia, Joseph. 2014. "Individual protest participation in the united states: Conventional and unconventional activism." Social Science Quarterly 95 (1): 111-131.

Dunning, Thad. 2012. Natural Experiments in the Social Sciences. Cambridge: Cambridge University Press.

Earl, Jennifer. 2011. "Political repression: Iron fists, velvet gloves, and diffuse control." Annual Review of Sociology 37 (1): 261-284. 
Earl, Jennifer. 2003. "Tanks, tear gas, and taxes: Toward a theory of movement repression." Sociological Theory 21 (1): 44-68.

Earl, Jennifer, and Sarah A. Soule. 2010. "The Impacts of Repression: The Effect of Police Presence and Action on Subsequent Protest Rates." Research in Social Movements, Conflicts and Change 30 (January): 75-113.

Earl, Jennifer, Sarah A Soule, and John D. McCarthy. 2003. "Protest under Fire? Explaining the Policing of Protest." American Sociological Review 68 (4): 581.

Eck, Kristine. 2012. "In data we trust? A comparison of UCDP GED and ACLED conflict events datasets." Cooperation and Conflict 47 (1): 124-141.

Ellefsen, Rune. 2021. "The Unintended Consequences of Escalated Repression." Mobilization 26 (1): 87-108.

Esberg, Jane. 2021. "Anticipating dissent: The repression of politicians in Pinochet's Chile." Journal of Politics 83 (2): 689-705.

Francisco, Ronald. 2004. "After the Massacre: Mobilization in the Wake of Harsh Repression." Mobilization 9 (2): 107-126.

García, Cristóbal, Marisa Von Bülow, Javier Ledezma, and Paul Chauveau. 2014. "What can Twitter tell us about social movements' network topology and centrality? Analysing the case of the 2011-2013 Chilean student movement." International Journal of Organisational Design and Engineering 3 (3/4): 317-337.

García-Ponce, Omar, and Benjamin Pasquale. 2015. How Political Repression Shapes Attitudes toward the State, Unpublished manuscript.

Goldstone, Jack, and Charles Tilly. 2001. "Threat (and Opportunity): Popular Action and State Response in the Dynamics of Contentious Action." In Silence and Voice in the Study of Contentious Politics. Cambridge University Press.

Gurr, Ted Robert. 2011. Why Men Rebel. Boulder, CO: Paradigm Publishers.

Gurr, Ted Robert, and Will H. Moore. 1997. "Ethnopolitical Rebellion: A Cross-Sectional Analysis of the 1980s with Risk Assessments for the 1990s." American Journal of Political Science 41 (4): 1079.

Haar, Rohini J., Vincent Iacopino, Nikhil Ranadive, Madhavi Dandu, and Sheri D. Weiser. 2017. "Death, injury and disability from kinetic impact projectiles in crowd-control settings: A systematic review." BMJ Open 7 (12): 1-9.

Hernán, Miguel A., and James M. Robins. 2006. "Instruments for causal inference: An epidemiologist's dream?" Epidemiology 17 (4): 360-372.

Hess, David, and Brian Martin. 2006. "Repression, backfire, and the theory of transformative events." Mobilization 11 (2): 249-267. 
Honari, Ali. 2018. "From 'the effect of repression' toward 'the response to repression'." Current Sociology 66 (6): 950-973.

INDH. 2019. 22 personas lesionadas, denuncias de desnudamientos, torturas y malos tratos por Fuerzas de Orden dejan jornadas de protestas. Accessed June 4, 2021. https://www.indh.cl/22-personas-lesionadas-denuncias-de-desnudamientostorturas-y-malos-tratos-por-fuerzas-de-orden-dejan-jornadas-de-protestas/.

Jaouni, Ziad M, and John G O'shea. 1997. "Surgical management of ophthalmic trauma due to the Palestinian Intifada." Eye 11, no. 3 (May): 392-397.

Jiménez-Martínez, César. 2021. "The Instrumental Mediated Visibility of Violence: The 2013 Protests in Brazil and the Limitations of the Protest Paradigm." International Journal of Press/Politics 26 (3): 525-546.

Josua, Maria, and Mirjam Edel. 2015. "To Repress or Not to Repress-Regime Survival Strategies in the Arab Spring." Terrorism and Political Violence 27 (2): 289-309.

Kearns, Erin M., Victor Asal, James Igoe Walsh, Christopher Federico, and Anthony F. Lemieux. 2020. "Political Action as a Function of Grievances, Risk, and Social Identity: An Experimental Approach." Studies in Conflict and Terrorism 43 (11): 941-958.

Khawaja, Marwan. 1993. "Repression and Popular Collective Action: Evidence from the West Bank." Sociological Forum 8 (1): 47-71.

Lartizien, Rodolphe, Thomas Schouman, Mathieu Raux, Alexandre Debelmas, Sophie Lanciaux-Lemoine, Aurore Chauvin, Adélaide Toutee, et al. 2019. "Yellow vests protests: facial injuries from rubber bullets." The Lancet 394 (10197): 469-470.

Lichbach, Mark Irving. 1987. "Deterrence or Escalation ? The Puzzle of Aggregate Studies of Repression and Dissent." The Journal of Conflict Resolution 31 (2): 266-297.

Maduz, Linda. 2020. Contention and Regime Change in Asia. Cham: Springer International Publishing.

Magaloni, Beatriz, and Luis Rodriguez. 2020. "Institutionalized Police Brutality: Torture, the Militarization of Security, and the Reform of Inquisitorial Criminal Justice in Mexico." American Political Science Review 114 (4): 1013-1034.

Mausolf, Joshua Gary. 2017. "Occupy the government: Analyzing presidential and congressional discursive response to movement repression." Social Science Research 67:91-114.

Opp, Karl-Dieter. 1994. "Repression and Revolutionary Action." Rationality and Society 6 (1): 101-138.

Opp, Karl-Dieter, and Wolfgang Roehl. 1990. "Repression, Micromobilization, and Political Protest." Social Forces 69 (2): 521-547. 
Raleigh, Clionadh, Andrew Linke, Håvard Hegre, and Joakim Karlsen. 2010.

"Introducing ACLED: An armed conflict location and event dataset." Journal of Peace Research 47 (5): 651-660.

Rasler, Karen. 1996. "Concessions, repression, and political protest in the Iranian revolution." American Sociological Review 61 (1): 132-152.

Ritter, Emily Hencken, and Courtenay R. Conrad. 2016. "Preventing and responding to dissent: The observational challenges of explaining strategic repression." American Political Science Review 110 (1): 85-99.

Rocke, Laurence. 1983. "Injuries Caused by Plastic Bullets compared with those caused by Rubber Bullets." The Lancet 321 (8330): 919-920.

Rodríguez, Álvaro, Sebastián Peña, Isabel Cavieres, María José Vergara, Marcela Pérez, Miguel Campos, Daniel Peredo, et al. 2021. "Ocular trauma by kinetic impact projectiles during civil unrest in Chile." Eye 35 (6): 1666-1672.

Rogel, Ángel. 2019. Piñera pide perdón y anuncia agenda social que implicará "esfuerzo grande". Accessed February 22, 2022. https://www.diarioconcepcion.cl/politica/2019/10/23/pinera-pide-perdon-yanuncia-agenda-social-que-implicara-esfuerzo-grande.html.

Rojas, Carolina. 2019. Así las reprimen en Estado de Excepción: Mujeres denuncian golpizas, humillaciones y amenazas de violación. Accessed June 4, 2012. https://www.eldesconcierto.cl/nacional/2019/10/21/asi-las-reprimen-en-estadode-excepcion-mujeres-denuncian-golpizas-humillaciones-y-amenazas-deviolacion.html.

Sharp, Gene. 1973. The Politics of Nonviolent Action. New York: Porter Sargent.

Smithey, Lee A., and Lester R. Kurtz. 2018. "Smart" Repression." In The Paradox of Repression and Nonviolent Movements, edited by Lee A. Smithey and Lester R. Kurtz, 185-214. New York: Syracuse University Press.

Sovey, Allison J., and Donald P. Green. 2011. "Instrumental variables estimation in political science: A readers' guide." American Journal of Political Science 55 (1): 188-200.

Sullivan, Christopher M., Cyanne E. Loyle, and Christian Davenport. 2012. "The Coercive Weight of the Past: Temporal Dependence and the Conflict-Repression Nexus in the Northern Ireland "Troubles"." International Interactions 38 (4): 426-442.

Sutton, Jonathan, Charles R. Butcher, and Isak Svensson. 2014. "Explaining political jiu-jitsu: Institution-building and the outcomes of regime violence against unarmed protests." Journal of Peace Research 51 (5): 559-573.

Tarrow, Sidney. 1994. Power in Movement. Social Movements and Contentious Politics. New York. 
Tilly, Charles. 1978. From Mobilization to Revolution. From Mobilization to Revolution. McGraw-Hill.

Van Zomeren, Martijn, Russell Spears, Agneta H. Fischer, and Colin Wayne Leach. 2004. "Put your money where your mouth is! Explaining collective action tendencies through group-based anger and group efficacy." Journal of Personality and Social Psychology 87 (5): 649-664.

Waddington, Peter A. J. 1997. The Policing of Mass Demonstration in Contemporary Democracies, Controlling Protest in Contemporary, Historical and Comparative Perspective, Working Paper EUI RSC; 1997/06. European University Institute.

Young, Lauren E. 2019. "The Psychology of State Repression: Fear and Dissent Decisions in Zimbabwe." American Political Science Review 113 (1): 140-155. 